\title{
Writing anxiety and its causes of pre-service teachers in an EFL context: Preliminary study
}

\author{
Dyah Sunggingwati \\ Faculty of Teacher Training and Education \\ Mulawarman University, Indonesia \\ sunggingwati@gmail.com
}

\begin{abstract}
This study investigated writing anxiety and its causes with 35-pre service teachers of English education department of Mulawarman University. Second Language Writing Anxiety Inventory (SLWAI) by Cheng (2004) were administered to measure writing anxiety of second language in terms of Somatic Anxiety, Avoidance Behavior, and Cognitive Anxiety. The results show that showed that the students cognitive anxiety is the most dominant experienced by the students $(37.4 \%)$, followed avoidance behavior and somatic anxiety with $32.6 \%$ and $29.9 \%$ respectively. Related to cognitive anxiety the results implied that the students participated in this study are not worried if their writing are worse than their classmates or to be evaluated or receive poor grade. The results of somatic anxiety indicate that writing activity is unfavorable skill to be completed as the students are still tense when they are required to do writing composition. In avoidance behavior, the results implied that the students wrote English but if they are not asked they will not to do it.
\end{abstract}

Keywords-SLWAI; somatic anxiety; avoidance behavior; cognitive anxiety

\section{INTRODUCTION}

Among the four skills, writing has always received more considerations in the field of EFL scholars due to the ability to write in English is significant to provide students to be successful at a college level and their careers. Additionally, there is a required cognitive skill related to learning strategies that entail higher order of thinking such as analysis synthesis, and inference in the process of writing $[1,12,13,22]$.

Anxiety as a situation that a person has difficulty along the writing process, in spite of having the required writing skills [2]. The process writing approach may have positive impact depend on its characteristics. Writing is considered to be the most complex and difficult skill to master, and as a rule, it is more complex and difficult than writing in one's native language [3]. Writing presents a great confront for most students in academic context, both in the mother tongue and in an ESL $\backslash E F L$ contexts. As English has become the most popular language universally, the important of English writing cannot be too denied.

Due to the crucial role for learning English, learners' writing skill needs to reinforced through a practice. In doing the practice of writing, learners are very possible to face problems such as anxiety. For example, he/she feels worried whenever the teacher reads the writing or his/her mind goes blank when writing under time pressure. Such anxiety is one of the factors that affect the process of learning [4]. Anxiety is divided into three types namely cognitive anxiety, somatic anxiety, and avoidance anxiety. Cognitive anxiety refers to the cognitive aspect of anxiety experience, including negative expectations, preoccupation with performance and concern about others' perception [5]. Somatic anxiety refers to one's perception of the psychological effects of the anxiety experience, such as nervous and tension. Avoidance anxiety is a type of anxiety where the students avoid writing.

Writing anxiety is more of a fear of the writing process that outweighs the projected gain from the ability to write [6]. Writing anxiety is also defined as a label for one or a combination of feelings, beliefs, or behaviors that interfere with a person's ability to start, work on, or finish a given writing task that he or she is intellectually capable of doing [7] Gender difference was a significant factor influencing classroom anxiety [8,9]. Female students had lower test anxiety and fear of negative evaluation than male students did [10] additionally utilized FLCAS to direct a longitudinal study and received Daly's scientific classification: correspondence misgiving, apprehension of assessment, and test nervousness. She discovered understudies stay unaltered in correspondence dread and apprehension of assessment in four years of their undergraduate study [11].

Manage writing anxiety such as nervous, fear, avoidance and sometimes anger to respond to the writing assignment because research indicates that emotional responses can affect academic performance "over and above the influence of cognitive ability or motivation" $[12,14]$. This implies that the fear, anxiety or boredom could impact writer performance although $\mathrm{s} /$ he has knowledge and desire to achieve her/his writing goal, therefore to lessen these reactions will be beneficial for personal and intellectual merit. According to [15] anxiety is not permanent and could be context-specific. For example a student that experience anxiety in an ora presentation but not in the peers in group-work interaction.

In addition, [15] attempted to manipulate the anxiety level of beginning learners by asking them to think about and report either positive or negative events from their own experience in order to direct their attention to focus on writing an essay, instead of the language task. [15] considered their Focused Essay technique successfully altered the self-perceptions of the language learners. Those writing a relaxed essay showed more confidence with language skills than those writing an anxiety 
essay on the Can Do Scale. In addition, those writing a relaxed essay described more about successful experiences in speaking and understanding skills while those writing an anxiety essay almost exclusively portrayed speaking events.

Most of the available research on anxiety has examined undergraduates, with some research having been conducted on graduate students. [16] discovered that writing anxiety is a major factor that inhibits graduate students' writing of research proposals. He conducted a study using the Daly-Miller WAT and Self-Perception Profile for College Students to 97 graduate students. The findings intimate that high levels of writing apprehension correlated with low levels of perceived scholastic competence and perceived creativity. [16] also found that procrastination was a major issue that resulted from writing anxiety, which, he thought, explained why $50 \%$ of doctoral candidates in education do not complete their degrees. He conducted a study in which he gave 135 graduate students the WAT along with a test known as the Procrastination Assessment Scale, and he found a significant correlation between the WAT and the scores on the Fear of Failure, Task aversiveness, and Procrastination Assessment Scales, which led him to conclude that graduate student anxiety about writing is related to procrastination, which stems from fear of failure and task aversiveness.

Conducted a mixed methods study examining writing anxiety of selected of 85 male and female EFL students majoring in English language teaching at an Iranian University [17]. The students responded to the Second Language Writing Anxiety Inventory (SLWAI) by [18] and the results revealed that the majority of Iranian EFL students experienced high level of writing anxiety. Furthermore, somatic anxiety was the most common type of anxiety, followed by cognitive anxiety, and avoidance behavior. The students have a high level of anxiety because of a variety of reasons including instructional practices, feedback received from writing instructors, and linguistic knowledge level. [19] reported their creative project designed by the first author to help graduate students in the dissertation-writing process cope with writing anxiety. Doctoral students never complete their degrees, $20 \%$ of it giving up in the dissertation. One of the causes is writing anxiety.

Survey study to examine predictors of writing anxiety and writing self-efficacy, factors that may impede or enhance students' writing performance. About 127 college students (30 males, 97 females) of a public university on the southwestern Texas border were involved in this study [20]. The findings indicated that GPA and gender affected writing anxiety, and leisure writing and anxiety were significant predictors of writing self-efficacy.

Taking account the complexity of writing process, the role of anxiety in English writing as well as the context, the investigation of this study focuses on the pre-service teachers writing anxiety. Therefore, the formulated questions to guide the investigation are as follow:

- To what extent do the pre-service teachers experience anxiety in English writing?
- What factors are associated with anxiety of the preservice teachers in English writing?

\section{METHODS}

Participant. This study involve two classes of 35undergraduate students of English education department of Mulawarman University in East Borneo, Indonesia. The undergraduates are the pre-service students, in the $4^{\text {th }}$ semester, who take a course of Writing IV. Instrument. The data of this study were gathered from questionnaires of Second Language Writing Anxiety Inventory (SLWAI). The SLWAI constructed by [18] was administered to measure writing anxiety of second language in terms of Somatic Anxiety, Avoidance Behavior, and Cognitive Anxiety. The SLWAI consists of 22 items, scored on a five-point Likert response scale ranging from 1 (strongly disagree) to 5 (strongly agree). Seven of the items $(1,4,7,17,18,21$, and 22) are negatively worded and require reverse scoring before being summed up to yield total scores. The 22 items of the SLWAI can be divided into three categories of anxiety namely cognitive anxiety $(1,3,7,9,14,17,20,21)$, somatic anxiety $(2,6,8,11,13,15,19)$, and avoidance behavior $(4,5,10,12,16,18,22)$.

Procedures. As the data in this study used as preliminary research therefore only one instrument was applied. Simple descriptive statistics in terms of the percentage was applied for the questionnaire analysis.

\section{FINDINGS AND DISCUSSION}

The results and discussion of this study is presented in the following section. The Second Language Writing Anxiety Inventory (SLWAI) will be first discussed followed by the Causes of The Second Language Writing Anxiety Inventory (CSLWAI).

Finally, complete content and organizational editing before formatting. Please take note of the following items when proofreading spelling and grammar:

\section{A. The results of The Second Language Writing Anxiety Inventory (SLWAI)}

Define abbreviations and acronyms the first time they are used in the text, even after they have been defined in the abstract. Abbreviations such as IEEE, SI, MKS, CGS, sc, dc, and rms do not have to be defined. Do not use abbreviations in the title or heads unless they are unavoidable. 


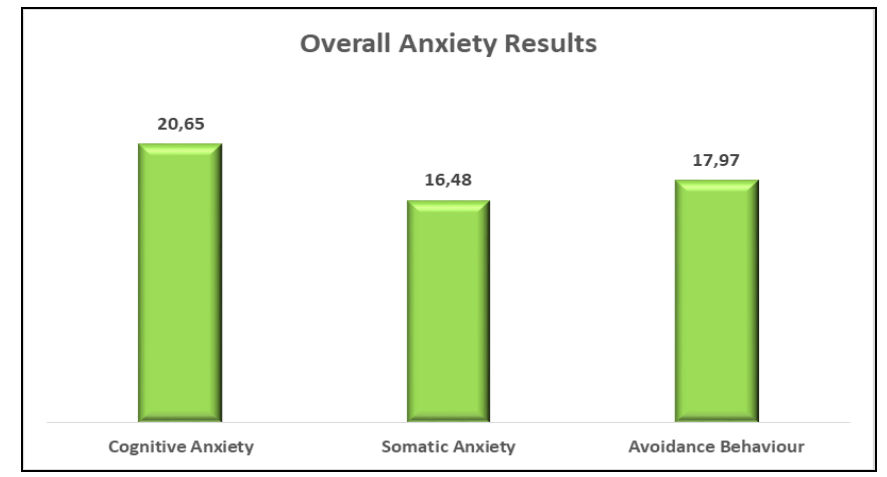

Fig. 1. Overall anxiety results

The results of SLWAI questionnaires reveal that cognitive anxiety is the most dominant experienced by the students (37.4\%), followed avoidance behavior and somatic anxiety with $32.6 \%$ and $29.9 \%$ respectively. Cognitive anxiety deals with the cognitive aspect of anxiety experience including negative expectations, preoccupation with performance and concern about others' perception. In addition, cognitive anxiety is basically the psychological (mental) side of anxiety, it acts on the brain, and has symptoms such as poor concentration, confusion, negative image and fear. Avoidance behavior links with the behavior aspect of the anxiety experience, avoidance writing. Somatic anxiety refers to physical changes in the body that occur when a person experiences anxiety. Somatic anxiety is the physical aspect of it and the acts upon the body, with symptoms such as "butterflies" in the stomach, tense muscles, sweating and nausea.

The results of this study, the students have highest cognitive experience followed by avoidance behavior and somatic anxiety, are in contrast with the previous study conducted by [17] that somatic anxiety was the most common type of anxiety, followed by cognitive anxiety, and avoidance behavior. Writing anxiety is a condition that affects writers and causes heightened stress and anxiety during the writing process. Graduate students often take on multiple responsibilities in their lives and academic studies. These tasks increase students' perceived stress and prevent them from completing their writing projects on time [24].

Details of the cognitive anxiety is shown in the following diagram.

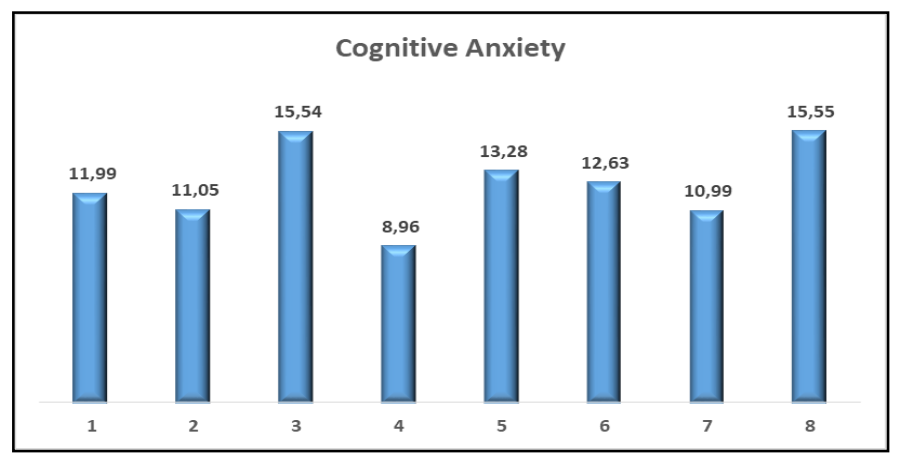

Fig. 2. Cognitive anxiety result
Cognitive anxiety has eight items that collaborate with the cognitive aspect of anxiety. The bar above shows that statements number three and eight are comparable with $15.54 \%$ and $15.55 \%$. These are "I don't worry that my English compositions are a lot worse than others" and I'm not afraid at all that my English compositions would be rated as very poor". Similar comparable responses occur for item number two and seven with $11.05 \%$ and $10.99 \%$ that "While writing English compositions, I feel worried and uneasy if I know they will be evaluated" and "I'm afraid of my English composition being chosen as a sample to be discussed in class". Meanwhile item number four received the least responses with $8.96 \%$ of "If my English composition is to be evaluated, I would worry about getting a very poor grade".

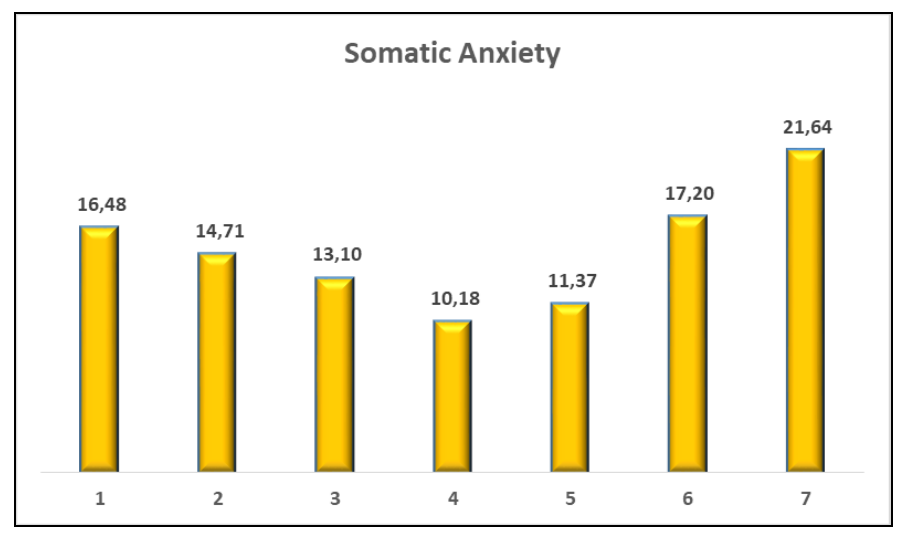

Fig. 3. Somatic anxiety

The bar of somatic anxiety that has seven items shows that each item obtains different numbers of responses and the highest percentage is item number seven "I usually feel my whole body rigid and tense when I write English compositions" (21.64\%) and the fewest percentage of the statement "My thoughts become jumbled when I write English compositions under time constraint" with $10.18 \%$. Statement number one ("I feel my heart pounding when I write English compositions under time constraint") and six (I freeze up when unexpectedly asked to write English compositions") achieved slightly similar responses with $16.48 \%$ and $17.20 \%$.

The avoidance behavior is presented in the following section.

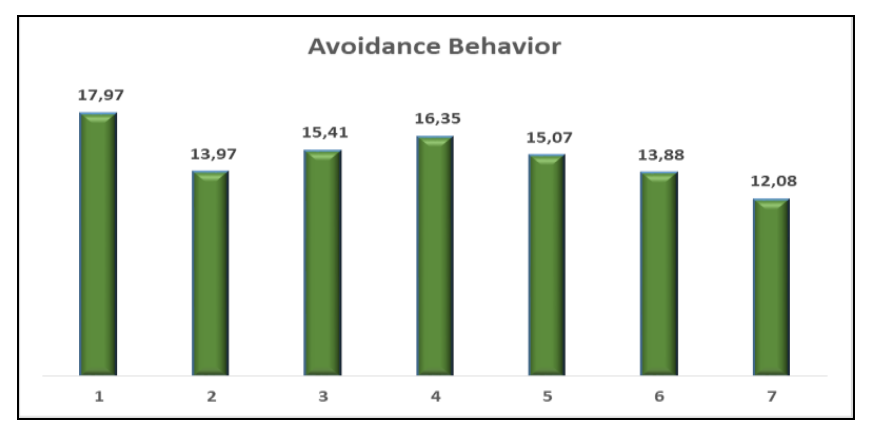

Fig. 4. Avoidance behavior result 
For avoidance behavior, the bar reveals that the highest percentage is the first statement of "I often choose to write down my thoughts in English" with 17.97\%, and the lowest one is the statement "Whenever possible, I would use English to write compositions". There are four statements that have similar percentages. Statement number three ("I do my best to avoid situations in which I have to write in English" and five ("I would do my best to excuse myself if asked to write English compositions) with $13.97 \%$ and $13.88 \%$; and statement number two and six have similar percentage ("I usually do my best to avoid writing English compositions") and ("I usually seek every possible chance to write English compositions outside of class").

B. The results of the questionnaires of Causes of The Second Language Writing Anxiety Inventory (CSLWAI) is presented in this section.

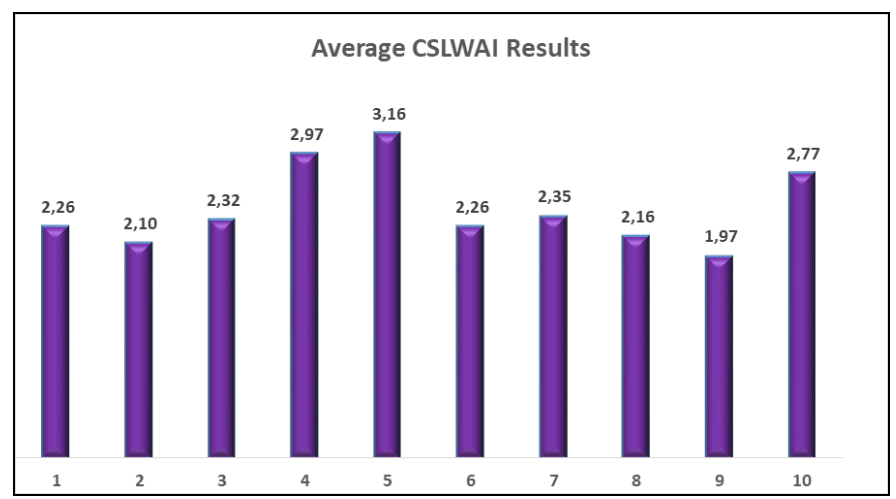

Fig. 5. Average CSLWAI results

The results of the Causes of Second Language Writing Anxiety Inventory (CSLWAI) which consists of 10 items show that the most responses were in the statement number five "I don't know what to write on the topic given by the teacher so I feel upset" with $12.99 \%$ and the fewest responses of $8.10 \%$ with the statement "I feel worry when I have to write under time constraints".

The second major cause of writing anxiety is "I don't have a good command of English writing techniques which makes me feel anxious" with $12.21 \%$ and "I have a low-confidence in English writing" with $11.38 \%$ as the third one. Other statements received similar percentage of responses ranged between $8.88 \%-9.66 \%$. [20] claimed that anxiety is a result of the lack of writing skills. However, according to [23]anxiety is not permanent and could be context-specific.

\section{CONCLUSION}

This study showed that the students cognitive anxiety is the most dominant experienced by the students (37.4\%), followed avoidance behavior and somatic anxiety with $32.6 \%$ and $29.9 \%$ respectively. Related to cognitive anxiety the results implied that the students participated in this study are not worried if their writing are worse than their classmates or to be evaluated or receive poor grade. The results of somatic anxiety indicate that writing activity is unfavorable skill to be completed as the students are still tense when they are required to do writing composition. In avoidance behavior, the results implied that the students wrote English but if they are not asked they will not to do it.

The results of this study, although are not supported with the empirical data and only from the questionnaire, implied that writing anxiety possibly still has important role in writing as the causes and type of anxiety are closely collaborated. Therefore, future study related to writing anxiety is better dealt with qualitative data to achieve better and comprehensive understanding about anxiety in writing

\section{REFERENCES}

[1] Bacha, N. N. (2002). Developing learners' academic writing skills in higher education: A study for educational reform. Language and Education, 16(3), 163-173.

[2] McLoad, S. (1987). Some thoughts about feelings: The affective domain and the writing process. College Composition and Communication, 38(4), 426-435.

[3] Bailey, S. (2003). Academic Writing: A Practical Guide for Students Cheltenham: UK: Nelson Thorenes Ltd.

[4] Kara, S. (2013). Writing Anxiety: A Case of Study on Students' Reason for Anxiety in Writing Classes. Anadolu Journal of Education Science International,3(1), 103-11.

[5] Cheng, Y.-S. (2004). A measure of second language writing anxiety: Scale development and preliminary validation. Journal of Second Language Writing, 13(4), 313-335

[6] Takahashi, A. (2009). Self-Perception of English Ability: Is It related to Proficiency and/or Class Performance. Niigata Studies in Foreign Languages and Cultures, 14: 39-48.

[7] Al-Sawalha, A. M. S, \& Chow, T. V. V. (2012).The Effects of Writing Apprehension in English on the Writing Process of Jordanian EFL Students at Yarmouk University. International Interdisciplinary Journal of Education, 1(1): 6-14.

[8] Cheng, Y. S. (2002). Factors associated with foreign language writing anxiety. Foreign Language Annals, 35(6), 647-656.

[9] Machida, S. (2001). Anxiety in Japanese-language class oral examinations. Sekai Nihongo Kyoiku, 11, 115-138.

[10] Hsu, S. C. (2009). Foreign Language anxiety among technical college students in English Classes. Journal of National Huwei University of Science \& Technology, 28(1), 113-126

[11] Salazar-Liu, Eva (2003). Foreign language anxiety among university students: A university students: A longitudinal study. In Yih-Lan Chen, Shih-peng, Wang \& Li-Jiuan Tsai(Eds.), The proceedings of 2003 International Conference and Workshop on TEFL \& Applied Linguistics. Taipei, Republic of China : Crane Publishing Company

[12] Irvin, L. Lennie. (2010). What Is "Academic" Writing? In Lowe, C. \& Zemliansky, P. (Eds), Writing Spaces: Readings on Writing Volume 1 (pp.3-17). West Lafayette, Indiana: Parlor Press

[13] Jun, Z. (2008). A comprehensive review of studies on second language writing. Papers in Applied Language Studies, 12, 89-123.

[14] Pekrun, Reinhard, Andrew J. Elliot, and Markus A. Maier (2009). "Achievement goals and achievement emotions: Testing a model of their joint relations with academic performance." Journal of Educational Psychology, 1, 115-135.

[15] Martinez, C.T., Kock, N., Cass, J. 2011. Pain and pleasure in short essay writing: Factors predicting university students' writing anxiety and writing self-efficacy. Journal of Adolescent \& Adult Literacy 54(5), 351-360.

[16] Onwuegbuzie, A. J. (2001). Writing apprehension and academic procrastination among graduate students. Perceptual and Motor Skills, $92,560-562$.

[17] Rezaei, M. M., Jafari, M. S., Younas, M. (2014). Iranian EFL Students Writing Anxiety: Levels, Causes, and Implications. English for Specific Purposes World, Vol. 15, Issue 42, 1-10. 
[18] Cheng, Y. S. (2004). A Measure of Second Language Writing Anxiety: Scale Development and Preliminary Validation. Journal of Second Language Writing, 13(4):313-335.

[19] Wynne, Craig; Guo, Yuh-Jen, \&Wang, Shu-Ching. 2014. Writing anxiety groups: A creative approach for graduate students. Journal of Creativity in Mental Health, 9, 366-379

[20] Martinez, C.T., Kock, N., Cass, J. 2011. Pain and pleasure in short essay writing: Factors predicting university students' writing anxiety and writing self-efficacy. Journal of Adolescent \& Adult Literacy 54(5), 351-360.
[21] Daud, N. M. \& Abu Kassim, N. L. (2005). Second language writing anxiety: Cause or effect. Malaysian Journal ofELT Research (MELTA).

[22] Tuan, L. T. (2010). Enhancing EFL learners' writing skill via journal writing. English Language Teaching, 3(3), 81-88.

[23] MacIntyre, P. D., \& Gardner, R. C. (1991), Investigating language class anxiety using the focused essay technique. The Modern Language Journal, 75(iii), 296-304. 